Nuntius Antiquus, Belo Horizonte, v. 11, n. 2, p. 47-70, 2015

\title{
Literatura e retórica na Institutio oratoria de Quintiliano e no Supremo Tribunal Federal brasileiro
}

\section{Literature and rhetoric in Quintilian's Institutio oratoria and Brazilian Supreme Court}

Charlene Martins Miotti

Departamento de Letras

Universidade Federal de Juiz de Fora

charlenemiotti@gmail.com

Wagner Silveira Rezende

Centro de Políticas Públicas e Avaliação da Educação

Universidade Federal de Juiz de Fora

wagner@caed.ufjf.br

Resumo: Este trabalho tem por objetivo apontar semelhanças entre alguns recursos argumentativos dos juízes do Supremo Tribunal Federal brasileiro e os preceitos de Quintiliano no sexto livro da Institutio oratoria quanto à manipulação das emoções do auditório e ao emprego de excertos literários em discursos forenses. Para tanto, compara-se seis citações diretas da Eneida de Virgílio, usadas pelo antigo rétor para ilustrar algumas estratégias de persuasão bem sucedidas, aos votos de cinco juízes em três hard cases recentes que atraíram muita atenção midiática: a ADI 3510 (lei de biossegurança sobre pesquisa com célulastronco), a ADI 4277 (reconhecimento da união homoafetiva) e a ADPF 54 (descriminalização do aborto em casos de nascituros diagnosticados com anencefalia). A comparação parece oportuna para demonstrar a atualidade e a circulação de um modus operandi retórico já discutido e aceito pelos antigos, mas que, modernamente, engendra certa ameaça ao mito do Direito imparcial e objetivo. 
Palavras-chave: Literatura; Retórica; Quintiliano; Institutio oratoria; Supremo Tribunal Federal.

Abstract: This paper aims to point out similarities between some argumentative resources from Brazilian Supreme Court's judges and Quintilian's precepts in the sixth book of Institutio oratoria concerning handling the emotions of an audience and the usage of literary excerpts in forensic speeches. Therefore, we compare six direct quotes from Virgil's Aeneid, used by the ancient rhetorician to illustrate some successful persuasion strategies, to five judges' votes in three recent hard cases that attracted much media attention: ADI 3510 (biosafety law on stemcells), ADI 4277 (recognition of homoaffective union) and the ADPF 54 (decriminalizing abortion in case of unborn diagnosed with anencephaly). The comparison seems appropriate to demonstrate the topicality and the circulation of a rhetorical modus operandi already discussed and accepted by ancient authors, that modernly, however, engenders a certain threat to the myth of impartial and objective Law.

Keywords: Literature; Rhetoric; Quintilian; Institutio oratoria; Brazilian Supreme Court.

Recebido em 14 de agosto de 2015 Aprovado em 19 de novembro de 2015

\section{Introdução}

Sabe-se que a retórica constitui, na Antiguidade, um corpo de doutrina extremamente amplo, em que ao mesmo tempo concorrem uma técnica, uma ciência, o ensino, a moral e a prática social.

Não é com Quintiliano, seguramente, que têm início a associação, a confusão ou a complementaridade entre a retórica e a ciência da literatura. Não estamos seguros de que realmente exista entre as $\tau \dot{\varepsilon} \chi v \alpha l$

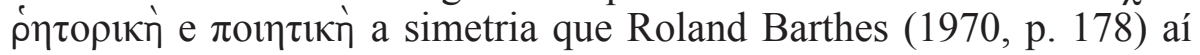
apontou ("no primeiro caso, trata-se de regular a progressão do discurso de ideia em ideia; no segundo, a progressão da obra de imagem em imagem") ou ainda aquela estabelecida por Diderot na primeira edição da Enciclopédia francesa (1765, tomo 14, verbete "retórica"): "A retórica está para a eloquência assim como a teoria está para a prática ou como 
a poética está para a poesia" (apud Dubois et alii, 1980, p. 12). Parece indubitável, no entanto, que ao longo do tempo e segundo cada autor, as relações entre as duas "artes" tenham se modificado, em razão da inerente transformação das próprias práticas que lhes correspondem. Para atribuir um sentido aceitável à intervenção complementar da retórica e da poética na constituição de uma teoria da literatura, poder-se-ia pensar em lhes designar, como domínios respectivos, a prosa e a poesia. Mas basta folhear os tratados retóricos antigos (e muitos modernos, ${ }^{1}$ como a Introdução à retórica de Olivier Reboul, 2004, que traz poemas inteiros de Charles Baudelaire, Victor Hugo, Pierre Corneille e Giacomo Leopardi, para citar poucos) para se verificar facilmente que a maioria dos exemplos provém de poetas.

Este trabalho pressupõe, assim sendo, uma relação orgânica entre retoricidade e literariedade, ali onde falham as definições estanques do modus operandi didático. Estamos operando da perspectiva de um entrelugar, admitindo a inevitável falência de uma abordagem que a considere como técnica desprovida de arte ou como arte desprovida de técnica.

No sexto livro da Institutio oratoria (96 d.C.), Quintiliano busca delimitar, definir, organizar e exemplificar os elementos envolvidos no processo de recriação planejada das paixões em um discurso. A formulação da "teoria dos afetos" (adfectum é sua tradução latina para

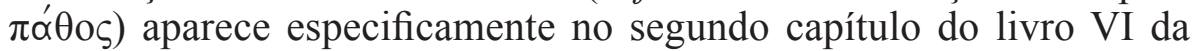
Institutio, sendo composta de trinta e seis parágrafos nos quais o autor pondera em que medida o apelo às emoções pode ser útil a um orador, sobretudo no fórum e, particularmente, na peroração, quando todos os recursos da lógica e da razão já foram esgotados. Neste contexto, chamam a atenção seis citações diretas da Eneida, apontadas como exemplos de estratégias de persuasão bem sucedidas. Assim, interessa-nos, como primeiro passo, avaliar a proposta de complementaridade entre retórica e poesia que subjaz ao opus magnum de Quintiliano.

Uma vez apontada essa relação complementar, o próximo passo será a busca por uma comparação entre o uso dos afetos e da poesia de Virgílio, em Quintiliano, e o uso dos afetos e da literatura como

\footnotetext{
${ }^{1}$ Se ampliarmos o escopo da poesia para a literatura em prosa, temos o exemplo do próprio Tratado da argumentação: a nova retórica de Perelman \& Olbrechts-Tyteca, 2005, cuja primeira citação, na p. 17, é de Alice no País das Maravilhas e onde se lê, na p. 25, o primeiro dos muitos exemplos extraídos do romance Tristam Shandy de Laurence Sterne.
} 
argumentos para que decisões sejam estabelecidas no âmbito do Direito, mais especificamente, no contexto do Supremo Tribunal Federal brasileiro (STF). O objetivo desse confronto é apontar as muitas simetrias entre a proposta de Quintiliano, pensada e escrita no final do século I d.C., e o que ocorre no fazer jurídico de um tribunal vinte séculos depois, muito além das fronteiras do mundo romano. A despeito das diferenças temporais e factuais entre a Institutio oratoria e a seara decisória do STF, o cotejo é frutífero para o reconhecimento da atualidade do tema, que interessou não somente ao rétor hispânico, mas, antes dele e principalmente, a Aristóteles (cuja influência na obra de Quintiliano é evidente), e que mostra, ainda hoje, sua importância.

Antes de passar ao exercício ao qual este trabalho se propõe, será preciso explicitar algumas características do STF, do ponto de vista de sua tomada de decisão, bem como os casos que, uma vez analisados, servirão como base da comparação supracitada. A isso o próximo tópico se dedica. Em seguida, são elencados os trechos do sexto livro da Institutio oratoria nos quais os afetos são evocados, através da poesia de Virgílio, como estratégias retóricas. Ao fim de cada uma dessas análises, exemplos retirados de decisões do STF são apresentados para estabelecer um paralelismo entre a proposta de Quintiliano e a forma como o tribunal tem estabelecido suas decisões em casos particularmente difíceis (que abordaremos a seguir).

\section{A retórica e as decisões do Supremo Tribunal Federal brasileiro}

A escolha do STF como instância para estabelecer uma análise do uso da literatura (não somente da poesia) e dos afetos como elementos retóricos, na esteira de Quintiliano, exige uma justificativa que encontra respaldo nas próprias características da corte, assim como no papel que o tribunal passou a desempenhar no Brasil no período seguinte à promulgação da Constituição Federal de 1988. Posicionado como a corte suprema na hierarquia do judiciário brasileiro, o STF passou a encabeçar as decisões de maior repercussão social no país. Tais decisões, em muitos casos, ultrapassam a seara meramente jurídica, visto que as discussões que suscitam e suas consequências avançam em direção às esferas política, sociológica, econômica, antropológica, religiosa etc.

Isso faz com que o pretenso isolamento do Direito, defendido pelos iniciados no campo (a expressão é de Bourdieu, 2012) como 
fundamento de sua neutralidade (o Direito se decide com base no próprio Direito), seja colocado em xeque. As querelas apresentadas ao STF, especialmente as que se enquadram na definição de hard case, exigem dos juízes uma argumentação mais ampla do que aquela fornecida apenas pelo Direito. Assim, argumentos externos ao âmbito estritamente jurídico passam a integrar as decisões. A literatura será um componente desses argumentos. Ao lado disso, o Direito sempre buscou, em seu discurso, se afastar das paixões como aspecto constituinte de seu fazer decisório, sob um suposto princípio de imparcialidade. Na prática, contudo, nunca pôde evitar que os afetos fossem parte integrante de seus procedimentos.

Os hard cases, expressão utilizada por Ronald Dworkin (2002) para definir os casos para os quais a legislação não possui uma resposta pronta, evidenciam a diversidade argumentativa ${ }^{2}$ que perpassa as decisões do STF. No entanto, Dworkin insiste na perspectiva de que, para superar as lacunas, o juiz deve se valer de uma argumentação estritamente jurídica. A despeito disso, podemos definir os hard cases, a partir de um escopo abrangente e tendo em vista a análise das decisões no STF brasileiro, como os casos que exigem um conjunto mais robusto e diversificado de argumentos para que um veredito seja estabelecido (locus, por excelência, da retórica), sendo caracterizados por sua repercussão social ${ }^{3}$ (REZENDE, 2014). A experiência demonstra que não há limites claros ${ }^{4}{ }^{4}$ nesse conceito, em relação aos tipos de argumento dos quais os juízes se valerão para decidir.

Nos casos difíceis, a argumentação é imperativa por vários fatores: i) não há uma solução clara e pronta, o que exigirá que a mesma seja construída argumentativamente; ii) nenhum caso levado à apreciação

\footnotetext{
${ }^{2}$ Aristóteles, ao tratar dos gêneros do discurso, na Retórica, já havia acentuado que os argumentos de um gênero navegam por outros gêneros, sem que isso fosse tomado como um problema em si. Antes, trata-se de uma característica da retórica.

${ }^{3}$ A repercussão social acentuará a necessidade argumentativa da decisão, tanto em termos quantitativos quanto no que diz respeito à diversidade dos argumentos utilizados. ${ }^{4}$ Isso quer dizer que há limites para o tipo de argumentação utilizada no âmbito de um tribunal como o STF. No entanto, esses limites não são estanques. Não é possível precisar, de antemão, na maioria das vezes, o que será aceito como argumento legítimo. Essas fronteiras são construídas na própria prática argumentativa. Apesar disso, a título de exemplo, uma argumentação estritamente religiosa, do tipo "minha decisão é essa porque eu sou católico", dificilmente seria aceita como uma justificativa legítima. Contudo, argumentos de outra natureza, que não a jurídica, como veremos com o exemplo da literatura, são largamente utilizados para reforçar e mesmo legitimar decisões.
} 
judicial pode ficar sem resposta (princípio da proibição do non liquet), ${ }^{5}$ ou seja, os juízes, mesmo em dúvida ou inseguros, devem decidir; iii) todos os vereditos, por imperativo do próprio ordenamento, devem ser justificados, e os juízes buscam produzir justificativas para os seus pares no tribunal, para a sociedade como um todo e para si próprios (MAGALHÃES, 2003, p. 54). O fundamento ou a motivação de uma decisão deve ser pautado pelos argumentos mais capazes de produzir convencimento. Com isso, os afetos e os argumentos de outras naturezas passam a concorrer para gerar persuasão. ${ }^{6}$

Os hard cases escolhidos para nossa análise, todos eles submetidos ao $\mathrm{STF}$, foram a $\mathrm{ADI}^{7} 3510$, que buscava a declaração de inconstitucionalidade do art. $5^{\circ}$ da lei de Biossegurança (11.105/2005), no que tange à possibilidade de pesquisa com células-tronco embrionárias no Brasil; a ADI 4277, que buscava o reconhecimento da união homoafetiva, e de todas as suas consequências, no país; e a $\mathrm{ADPF}^{8} 54$, que visava à descriminalização do aborto em casos de nascituros portadores de anencefalia. Em todos eles, as características típicas dos hard cases se fazem presentes: não havia uma resposta pronta no Direito, os juízes teriam que construir argumentativamente a decisão e os casos versavam sobre temas polêmicos, de grande repercussão social. Com isso, veremos nos $\operatorname{votos}^{9}$ dos ministros a utilização de argumentos extrajurídicos (aqui destacaremos os literários, embora eles sejam de inúmeras outras naturezas), bem como o recurso aos afetos, tática longamente discutida por Quintiliano.

\footnotetext{
5 A expressão latina significa 'não é claro', 'não está claro'. No Direito romano, era permitido que os juízes se abstivessem de decidir, caso a questão que lhes era submetida não apresentasse uma solução clara. Sem uma resposta jurídica para dar fim ao julgamento, o juiz poderia deixar de julgar. Essa não é mais uma opção para o juiz no Direito brasileiro moderno. Nosso ordenamento jurídico assegurou, através de inúmeros dispositivos, o princípio da proibição do non liquet: art. 126 do Código de Processo Civil; art. $4^{\circ}$ da Lei de Introdução do Código Civil; e o inciso XXXV, do artigo $5^{\circ}$ da Constituição Federal de 1988.

${ }^{6}$ Entretanto, isso não significa, necessariamente, que a persuasão, seguindo a perspectiva de Aristóteles (Retórica, 1355a), deva ser obtida a qualquer custo. O filósofo vincula a persuasão à observância da técnica e de elementos éticos.

${ }^{7}$ Ação direta de inconstitucionalidade. Para mais, cf. Rezende (2010b, p. 128).

${ }^{8}$ Arguição de Descumprimento de Preceito Fundamental. Para mais, cf. Medina (2005).

${ }^{9}$ Como a decisão de cada ministro (juiz) é chamada no âmbito do STF.
} 


\section{Literatura e Retórica em Quintiliano e no Supremo Tribunal Federal}

Já na Retórica (1403b), Aristóteles observa que a pronunciação "assenta na voz, ou seja, na forma como é necessário empregá-la de acordo com cada emoção (por vezes forte, por vezes débil ou média) e como devem ser empregados os tons, ora agudos, ora graves ou médios, e também quais são os ritmos de acordo com cada circunstância". ${ }^{10}$ Tendo reconhecido que "existe algo deste gênero na retórica, tal como na poesia", ${ }_{11}$ Aristóteles sugere que um orador que pretenda despertar emoções em seu auditório deve saber como empregar intensidade ou volume, harmonia e ritmo. ${ }^{12}$

Na esteira de Cícero (De or. III, 217-220), Quintiliano não apenas aponta a relação e interdependência entre técnica e arte na prática forense: ele demonstra a seus jovens aprendizes como utilizar as emoções a seu favor. Uma das estratégias que o orador hábil pode empregar para suscitar $\pi \alpha ́ \theta 0 \varsigma$ em seu auditório é a recitação de poemas. No segundo capítulo do livro VI da Institutio oratoria, Quintiliano cita a Eneida seis vezes, ao longo de seus trinta e seis parágrafos. Será útil recuperar aqui a opinião de Quintiliano sobre o poeta augustano, tal como aparece no seu próprio livro dez:

Cabe-nos a tarefa de tratar dos autores romanos, estabelecendo-se idêntica ordenação. E assim, tal como entre eles Homero, entre nós Virgílio terá dado o começo, o mais auspicioso. Sem sombra de dúvida, dentre todos os poetas gregos e romanos que escreveram este gênero de poesia, ele é o mais próximo de Homero. 86. Usarei das mesmas palavras que eu, ainda jovem, ouvi de Domício Afro. A mim, que o interrogava a respeito de quem mais

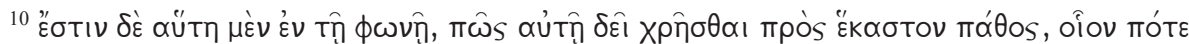

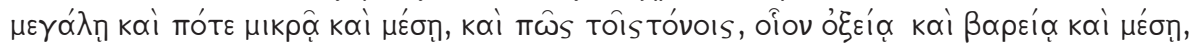

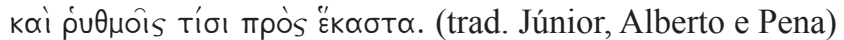

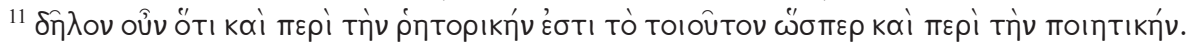
(trad. Júnior, Alberto e Pena)

${ }^{12}$ No Orator (140-238), Cícero procura definir qual seja o melhor estilo oratório (genus orationis optimorum), cujo emprego caracteriza o orador perfeito. Um elemento essencial para a desenvoltura de tal estilo é o uso correto e eficiente da "prosa rítmica", que Cícero sistematizou detalhadamente neste livro.
} 
se aproximasse de Homero, ele disse: "O imediatamente seguinte é Virgílio, no entanto, ele está muito mais perto do primeiro do que do terceiro". Por Hércules, conquanto tenhamos de ceder a passagem àquela Natureza Celestial e Imortal, Homero, no entanto, muito de dedicação cuidadosa e diligência existiu em Virgílio pelo fato de que o esforço de elaboração lhe foi muito mais exigido. [...] Todos os demais poetas o seguem, mas de longe. ${ }^{13}$ (Inst. or. X, 1, 85-86)

Será útil, ainda, repassar as seis citações em seu contexto, a fim de analisá-las propriamente. Às citações em Quintiliano serão comparadas estruturas argumentativas semelhantes observadas no STF, no bojo de casos difíceis apresentados à corte. É importante salientar que, se Quintiliano se pronuncia através do gênero didático, conduzindo seus pupilos à apreciação das melhores técnicas do ofício oratório por meio de uma vasta casuística (este, inclusive, um de seus maiores trunfos para a posteridade) ${ }^{14}$ seu próprio estilo não deixa de espelhar, ora de modo mais flagrante (como se verá adiante no passo VI, 2, 31), ora discretamente, o esmero retórico que recomenda a seus leitores. Assim, mesmo que o antigo autor se dedique na Institutio oratoria ao ensino de retórica e não à apresentação de uma peça oratória propriamente dita (como no caso dos votos dos ministros do STF), julgamos válido o cotejo diacrônico e diatópico das estratégias que Quintiliano explicitou didaticamente na

${ }^{13}$ Trad. Antônio Martinez de Rezende, 2010a, p. 207-209: LXXXV. Idem nobis per Romanos quoque auctores ordo ducendus est. Itaque ut apud illos Homerus, sic apud nos Vergilius auspicatissimum dederit exordium, omnium eius generis poetarum Graecorum nostrorumque haud dubie proximus. LXXXVI. Vtar enim uerbis isdem quae ex Afro Domitio iunenis excepi, qui mihi interroganti quem Homero crederet maxime accedere "secundus" inquit "est Vergilius, propior tamen primo quam tertio". Et hercule ut illi naturae caelesti atque immortali cesserimus, ita curae et diligentiae uel ideo in hoc plus est, quod ei fuit magis laborandum, et quantum eminentibus uincimur, fortasse aequalitate pensamus. Ceteri omnes longe sequentur.

${ }^{14}$ Jon Hall (2004, p. 143) ressalta que "é frustrante quão pouca evidência temos sobre as próprias práticas de atuação oratória de Cícero. Enquanto dispomos dos textos de mais de cinquenta de suas orações, poucos detalhes são fornecidos por seus contemporâneos sobre como ele transformou essas palavras em efetivas performances ao vivo. Não menos frustrante é o fato de que o próprio Cícero revela muito pouco sobre essas técnicas em seus tratados retóricos". 
Roma imperial e que ainda são empregadas em discursos modernos cujas intenções, vale assinalar, também não estão desprovidas de certa carga preceptística para a sociedade.

A primeira citação (ainda que não apresentada como tal) aparece no sétimo parágrafo (doravante, todas as traduções de Quintiliano são nossas):

7. Assim, a sentença do juiz mostra o que produziram as provas e as testemunhas, mas o juiz comovido pelo orador, enquanto ainda está sentado e ouvindo, dá indícios do que sente. Por ventura ele não terá proferido a sentença em público quando os olhos estiverem cheios de lágrimas? - isso é o que ocorre na maior parte das perorações. Aí se empenha, sobretudo, o orador, pois eis todo o ponto, $o$ trabalho mais duro, ${ }^{15}$ sem o qual todo o resto é vazio, árido, fraco, desagradável: a tal ponto, que o espírito e a alma do ofício oratório, por assim dizer, têm sua sede nos afetos. ${ }^{16}$ (Inst. or. VI, 2, 7)

Ainda que Quintiliano introduza o pronome anafórico eius na famosa frase de Virgílio, a referência é inequívoca: o conselho que a Sibila de Cumas dá a Eneias sobre a dificuldade em retornar do mundo inferior (hoc opus, hic labor est, Eneida VI, 129). A expressão se tornou proverbial, como se sabe, para indicar a parte mais adversa em qualquer missão, mas não podemos evitar a leitura nas entrelinhas: para Quintiliano, dominar a arte de manipular emoções, especialmente na prática oratória, será tão complexo quanto voltar do mundo dos mortos.

No que diz respeito à centralidade dos afetos, podemos observar o voto proferido pelo ministro Ayres Britto no caso envolvendo o reconhecimento da união homoafetiva no Brasil (ADI 4277). O ministro estrutura seu voto, desde o início, demonstrando ser favorável a tal reconhecimento. Ele aponta que os problemas da resistência à união

${ }^{15}$ Trad. Carlos Alberto Nunes, 2014, p. 383.

${ }^{16}$ VII. Ita argumenta ac testes quid egerint pronuntiatio ostendit, commotus autem ab oratore iudex quid sentiat sedens adhuc atque audiens confitetur. An cum ille qui plerisque perorationibus petitur fletus erupit, non palam dicta sententia est? Huc igitur incumbat orator, hoc opus eius, hic labor est, sine quo cetera nuda ieiuna infirma ingrata sunt: adeo uelut spiritus operis huius atque animus est in adfectibus. 
homoafetiva no país estão relacionados ao conservadorismo e ao preconceito, baseados em uma leitura de mundo equivocada.

Para contornar tal problema, ele propõe o uso da razão, para, logo em seguida, recorrer novamente aos afetos. De acordo com Ayres Britto, e essa é a base de seus argumentos seguintes, o preconceito não encontra fundamento na verdade, no mundo material, mas, antes, ele se impõe à realidade. Em defesa da verdade, não uma absoluta, mas aquela contingencial, ele recorre à poesia de Fernando Pessoa:

Reverência ao valor da verdade que também se lê nestes conhecidos versos de Fernando Pessoa, três séculos depois da proclamação cartesiana: "O universo não é uma ideia minha./ A ideia que eu tenho do universo é que é uma ideia minha" (grifo no original, p. 13 do voto).

É curioso notar que o ministro defendia o valor da verdade com base em René Descartes. No entanto, é na literatura que ele buscará o argumento de autoridade para sua afirmação. Os versos de Pessoa funcionam, no voto do ministro, como um conectivo, uma ligação entre o fim de um primeiro argumento e o início do seguinte, convidando toda a sociedade para a reflexão sobre a subjetividade dos valores tradicionalmente aceitos na coletividade.

Mesmo com a defesa da força da "verdade", é com base nos afetos que Ayres Britto articula sua argumentação. Segundo o ministro, será o afeto, e não a reta razão, que dará o caminho mais seguro para o pronunciamento da decisão. Ele cita Platão (sem amor, não há filosofia) e Max Scheler (o ser humano é, antes de pensante, um ser amante) para afirmar que é com base no amor e na afetividade que uma decisão no caso da união homoafetiva pode ser construída e acatada. Nessa passagem do voto do ministro, vemos o recurso à literatura, porta-voz dos sentimentos que nos fazem humanos, como reforço ao argumento.

Se no voto de Ayres Britto as citações literárias conferem peso ao argumento, em Quintiliano ilustram a explicação teórica. A segunda citação poética no segundo capítulo do livro sexto evoca as palavras desesperadas de Andrômaca (Eneida III, 321-3), comparando seu destino ao de Polixena, sacrificada sobre a tumba de Aquiles depois da queda de Troia. A viúva de Heitor, como se sabe, lamenta ter se tornado escrava de Pirro Neoptólemo, filho de Aquiles: 
Com efeito, certas ações parecem graves por si mesmas, como o parricídio, o assassinato e o envenenamento, [enquanto] outras devem ser relatadas como tal. 22. Isso, então, acontece quando mostramos que nosso sofrimento é mais cruel do que as piores desgraças, como em Virgílio:

"Só a que foi feliz entre nós todas foi a virgem Priâmida que teve de morrer em sepulcro de inimigo frente aos muros de Troia"17

quão desesperado, pois, o caso de Andrômaca, se ele a compara à "feliz" Polixena. ${ }^{18}$ (Inst. or. VI, 2, 22)

Quintiliano aconselha, nesta passagem, que o orador habilidoso deve falar, dada a oportunidade, exatamente como Andrômaca. Seu sofrimento só pode ser medido e julgado se comparado ao mais hediondo aniquilamento pelo qual uma mulher poderia passar: ser sacrificada em oferta ao pior inimigo do seu povo. De maneira semelhante, ao expor os danos causados a um cliente por seu adversário, um bom orador deve ser capaz de manejar toda a amplificação que for necessária para conduzir o público a simpatizar com suas alegações. Em seguida, Quintiliano acrescenta ao exemplo de Andrômaca uma conceituação desta estratégia retórica:

24. E, de fato, nesse ponto está a força da eloquência: não é tanto para compelir o juiz a tomar uma decisão que teria sido direcionada pela própria natureza do fato, mas que desperte um sentimento que não há ou maior do que há. Esta é a figura chamada deinosis, discurso que acrescenta vigor às ações indignas, cruéis e odiosas; nesse mérito, Demóstenes se destacou mais do que outros oradores. ${ }^{19}$ (Inst. or. VI, 2, 24)

\footnotetext{
${ }^{17}$ As traduções da Eneida serão, doravante, de Agostinho da Silva, 2012.

${ }^{18}$ Nam quaedam uidentur grauia per se, parricidium caedes ueneficium, quaedam efficienda sunt. XXII. Id autem contingit cum magnis alioqui malis grauius esse id quod passi sumus ostenditur, quale est apud Vergilium: "O felix una ante alias Priameia uirgo, hostilem ad tumulum Troiae sub moenibus altis iussa mori" - quam miser enim casus Andromachae si comparata ei felix Polyxena.

${ }^{19}$ XXIV. Namque in hoc eloquentiae uis est, ut iudicem non in id tantum compellat in quod ipsa rei natura ducetur, sed aut qui non est aut maiorem quam est faciat adfectum.
} 
Logo depois, Quintiliano atesta que o elemento essencial para suscitar as emoções em outras pessoas, em sua opinião, será ele mesmo senti-las ( $c f$. De or. III, 189). Então, ele prossegue tentando responder à pergunta fundamental: como será possível criar essas emoções em nós mesmos, se, por definição, elas não estão sob nosso controle? $\mathrm{Na}$ formulação de Eric Dodds:

O homem grego havia sempre sentido a experiência da paixão como algo misterioso e aterrorizante, como a experiência de uma força que o habitava e o possuía muito mais do que alguma coisa possuída por ele. A própria palavra pathos é um testemunho disso: como o termo latino equivalente, passio, ela se refere a algo que acontece ao homem, algo de que ele é vítima passiva. Aristóteles compara o homem em estado de paixão aos homens adormecidos, loucos ou embriagados - a razão de todos eles está em estado de suspensão. (DODDS, [1951] 2002, p. 187)

Neste ponto, onde Quintiliano recorre a Virgílio para acentuar e ampliar o vigor de ações odiosas, buscando, dessa forma, ressaltar o sofrimento para, assim, fazer com que o interlocutor (Perelman chamará de "auditório") sinta esse mesmo sofrimento, o que aumenta a repulsa pela ação inicialmente descrita, podemos encontrar paralelos com o voto do ministro Luiz Fux, no bojo da ADPF 54, envolvendo a discussão sobre a descriminalização do aborto de feto anencéfalo.

Fux votou a favor da descriminalização, e sua argumentação, majoritariamente, se ancorou na construção de uma imagem odiosa em relação ao impedimento de realização do aborto nesses casos. A construção da imagem odiosa é correlata do despertar da compaixão em relação aos casos de mães que tiveram que passar por essa experiência. Recorrendo ao páthos de seus interlocutores (os demais juízes e sociedade como um todo), Luiz Fux constrói seu argumento de forma quase literária, ao narrar o exemplo de sofrimento de uma mulher que perdeu o filho anencéfalo. A passagem não é retirada de nenhuma obra literária, mas poderia sê-lo, tamanha a semelhança com a literatura que sua estrutura demonstra:

Haec est illa quae deinosis uocatur, rebus indignis asperis inuidiosis addens uim oratio, qua uirtute praeter alias plurimum Demosthenes ualuit. 
Primavera de 1980. Jovens casais aguardam na fila do Hospital São José, Rio de Janeiro, o momento sublime do parto. Ali, sonhos se multiplicam na imaginação das mulheres que estão prestes a dar à luz. A figura do filho amado crescendo, se desenvolvendo e preenchendo a vida daqueles que o esperam é o que certamente ocorre àquelas gestantes. Em contraste, chamava a atenção de todos uma jovem moça, que também aguardava na mesma fila, em copioso pranto, juntamente com o seu marido. A comoção se justificava: no lugar de sonhos cultivados, esta gestante assistiu durante nove meses ao funeral de seu filho. O pequeno caixão branco por ela encomendado era o símbolo de um ritual tão triste quanto severo com uma mulher que, em verdade, jamais conseguirá ser mãe do filho que gestava. (grifo nosso, p. 1 do voto)

O trecho começa com a descrição de uma cena envolta pela felicidade, qual seja, a expectativa pelo nascimento de um filho. Contudo, a descrição seguinte (grifada) causa consternação: a dor de uma mãe que acaba de perder um filho, a imagem do caixão da criança e a destruição de um sonho. A descrição do sofrimento é acentuada pela literariedade com que o ministro descreve a cena, que tem seus efeitos sobre o páthos dos interlocutores ampliados. Fux buscava convencer os pares de que o aborto de anencéfalos deveria ser autorizado pelo ordenamento jurídico brasileiro, e, para tanto, constrói um argumento que coloca como odiosa a postura de quem não apoia tal decisão. Luiz Fux descreve o caso dessa mãe como o sofrimento mais cruel, de modo que seus interlocutores sejam capazes de, se colocando em seu lugar, ter a medida de tamanha dor. A estrutura do argumento não difere, nesse ponto, daquela utilizada por Quintiliano, no exemplo de Andrômaca e Polixena.

Especificamente no que tange à estratégia de conceder vigor às ações cruéis e odiosas, o exemplo do ministro Eros Grau, no julgamento da ADI 3510, sobre a pesquisa com células-tronco, é lapidar. Não estamos diante de uma ação odiosa do ponto de vista físico, mas, antes, moral, característica que não diminui em nada o efeito de reforçar o aspecto odioso do ato.

Eros Grau votou pela constitucionalidade da lei de Biossegurança, a favor da pesquisa com células-tronco, mas condicionou seu voto à observância de uma série de elementos. Seu temor era, uma vez autorizadas livremente as pesquisas, que as células-tronco fossem 
utilizadas indevidamente do ponto de vista ético. Além disso, o uso mercadológico das pesquisas era uma preocupação evidente para o ministro. Com isso, Eros procurou descrever o uso mercadológico das células-tronco como um perigo, como um mal, encarnado na manipulação genética. A pesquisa poderia gerar esse mal, que precisa ser controlado. Contudo, o bem que ela poderá fazer pesa para que Eros Grau vote pela constitucionalidade da lei. Para construir a imagem de mal, o ministro recorre a São Tomás de Aquino:

Não é recomendável, contudo, que tais riscos sejam dessa forma combatidos. A prudência indica dê-se ao mal o tratamento a que Tomás de Aquino faz alusão na Segunda Parte da Segunda Parte, questão 10, artigo 11 da Suma Teológica, ao cuidar dos ritos dos infiéis: "O governo humano deriva do governo divino e o deve imitar. Deus, porém, ainda que seja onipotente e sumamente bom, permite que aconteçam alguns males no universo, que poderia impedir, para que não suceda que, uma vez supressos, suprimam-se também grandes bens ou sigamse males piores. Assim também no governo humano: os que governam toleram, com razão, certos males, para que alguns bens não sejam impedidos ou não sucedam males piores, como diz Agostinho: 'Suprime as meretrizes da sociedade humana e perturbarás tudo com a libidinagem'. Assim, pois, ainda que os infiéis pequem em seus ritos, eles podem ser tolerados ou por causa do bem que deles provêm ou por algum mal evitado". (p. 11 do voto)

Ao comparar a manipulação genética com outros males, usando a perspectiva tomista, Eros amplia, vigorosamente, a ideia da pesquisa descontrolada como um mal a ser combatido. O objetivo é produzir uma concepção, que pode não ter sido considerada a princípio pelos demais ministros, de que, com um bem, um mal pode vir junto. No caso do uso mercadológico do material genético, Eros reforça essa ação como odiosa e repulsiva, comparando-o com outros males morais da humanidade.

Ainda quanto aos afetos em Quintiliano, cabe questionar quais seriam, portanto, as estratégias recomendadas para controlar uma força tão poderosa e indomável como aquela oriunda das paixões. Tanto a

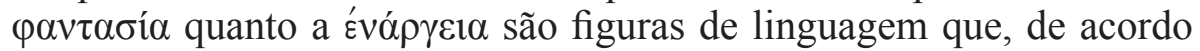
com o rétor, devem ser empregadas na criação de um desejável efeito de 
presença, capaz de converter um simples ouvinte em testemunha ocular. Em suas palavras:

29. Mas como fazer para que sejamos comovidos? $\mathrm{Na}$ verdade, as emoções não estão em nosso poder. Tentarei, ainda, falar a esse respeito. $\mathrm{O}$ que os gregos chamam de phantasias, a nós convém que chamemos de uisiones segundo as quais, imagens de coisas ausentes são de tal modo descritas que as visualizamos como se estivessem presentes e diante dos nossos olhos -, qualquer pessoa que as tiver apreendido bem será habilíssima em suscitar emoções. ${ }^{20}$ (Inst. or. VI, 2, 29-30)

Aristóteles dá ao poeta um conselho curiosamente semelhante:

Devem estruturar-se os enredos e completá-los com a elocução, pondo-os, o mais possível, diante dos olhos. Assim, vendo-os com toda a clareza, como se estivesse perante os próprios factos, o poeta poderá descobrir o que é apropriado e não deixará escapar nenhuma contradição. ${ }^{21}$ (Poética, 1455a)

Em relação à utilização do recurso de fazer ver, como se estivéssemos presentes, aquilo que se narra, suscitando emoções nos interlocutores, encontramos exemplo no voto do ministro Ricardo Lewandowski, em ocasião da decisão acerca da inconstitucionalidade das pesquisas com células-tronco embrionárias (ADI 3510). O ministro foi a favor da declaração da inconstitucionalidade das pesquisas e seu argumento se baseou, essencialmente, em expor os problemas éticos em torno destas pesquisas, além de reforçar os perigos advindos de tal prática.

${ }^{20}$ XXIX. At quo modo fiet ut adficiamur? Neque enim sunt motus in nostra potestate. Temptabo etiam de hoc dicere. Quas phantasias Graeci uocant (nos sane uisiones appellemus), per quas imagines rerum absentium ita repraesentantur animo ut eas cernere oculis ac praesentes habere uideamur, has quisquis bene ceperit is erit in adfectibus potentissimus.

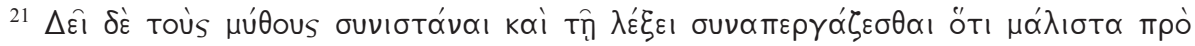

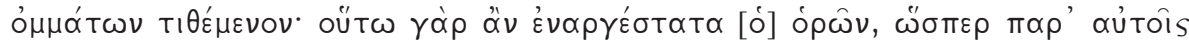

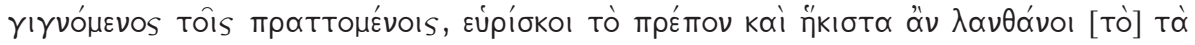

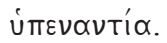


Para Lewandowski, a ciência, representada, no caso analisado, pelo avanço das pesquisas com células-tronco, não traz somente benefícios, como mostra a história da humanidade. Depois de enumerar, exaustivamente, os problemas que podem advir do desenvolvimento tecnológico, fazendo um contraponto com a ética, o ministro aponta que, além das vicissitudes que já conhecemos em relação ao excessivo desenvolvimento científico, outras certamente surgirão no horizonte social vindouro.

A partir de então, o argumento que se instala é do tipo ad terrorem, prevendo um possível futuro calamitoso e terrível para a humanidade, caso os avanços da tecnologia não sejam freados por uma regulação ética. O ad terrorem é uma espécie de argumento de caráter pragmático, ${ }^{22}$ através do qual o orador se vale das possíveis consequências de um ato (na argumentação de Lewandowski, consequências nefastas) para atribuir a mesma carga emocional e valorativa às causas. Assim, a visão pejorativa de um futuro desolador é imputada às causas da distopia, no caso, o avanço desenfreado da ciência, encarnado na figura das pesquisas com células-tronco.

O mais interessante no voto do ministro é que essa imagem é trazida ao interlocutor para produzir o efeito de presença, como se o mesmo fosse capaz de visualizar aquilo que está sendo narrado pelo orador, exatamente como na figura da phantasia, descrita por Quintiliano. Contudo, no caso do ministro Lewandowski, a emoção que pretende ser suscitada é o medo, o temor em relação ao futuro. E para produzir essa imagem, o ministro recorrerá à literatura de Huxley, Orwell e Kafka, como mostra a passagem a seguir:

Assim é que, hoje, busca-se proteção contra as manipulações genéticas, antevistas por Aldous Huxley em seu livro Admirável Mundo Novo (1930), as quais permitem, por exemplo, criar clones humanos e de animais, e em tese até mesmo - seja-me permitido o argumento ad terrorem - centauros, minotauros e sátiros, além de outros seres fantásticos, imaginados pela Mitologia Grega, ou contra

\footnotetext{
${ }^{22}$ Perelman define o argumento pragmático como "um argumento das consequências que avalia um ato, um acontecimento, uma regra ou qualquer outra coisa, consoante suas consequências favoráveis; transfere-se assim todo o valor destas, ou parte dele, para o que é considerado causa ou obstáculo". (2004, p. 11)
} 
a invasão da privacidade, a massificação e o totalitarismo, prenunciados por George Orwell em sua obra 1984 (1948), ou ainda contra a anônima e tentacular burocracia estatal e privada, prevista por Franz Kafka em seu romance $O$ Processo (1915). (p. 12 do voto)

Lewandowski, diante do impedimento de descrever, a partir de uma experiência que ele próprio, como ser de seu tempo, não possui em relação ao futuro, encontrará na literatura a possibilidade de evocar as imagens de um mundo devastado. Em Huxley, ele encontrará a descrição dos perigos da ciência, tema que o mobiliza em seu voto, mas, extrapolando tal temática, o ministro evoca também imagens dos perigos do totalitarismo e da burocracia estatal (elementos do mundo político), encontrados em Orwell e Kafka, respectivamente.

Assim, o argumento de Lewandowski se estrutura da seguinte maneira. As pesquisas com células-tronco, no estágio de desenvolvimento em que se encontram, devem ser declaradas inconstitucionais, pois não respeitam limites éticos. A situação pode se tornar ainda pior, e o futuro pode se apresentar como algo desolador, se nada for feito em contrário. A literatura nos dá exemplos de que isso é plenamente possível (no argumento do ministro, provável).

De volta a Quintiliano, as próximas quatro citações virgilianas ocorrem nos parágrafos 32 e 33, onde ele busca ilustrar como funciona

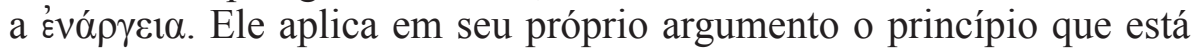
tentando demonstrar: note-se a descrição da cena de assassinato sendo composta imagem a imagem, enquanto uma dramática sequência de perguntas retóricas se desenvolve:

31. Lamento que um homem tenha sido assassinado: será possível que não terei diante dos olhos todas as circunstâncias para que o crime acontecesse? Não aparecerá de surpresa aquele assassino? A vítima não se assustará, não gritará ou até mesmo fugirá? Não verei o golpe fatal, não verei o corpo ferido cair? Não penetrará na alma o sangue, a palidez, o gemido e, finalmente, o último sopro de vida do homem? 32. Segue-se a enargueia, que por Cícero é denominada ilustração e evidência, cujo conceito remete mais à ideia de mostrar do que à de narrar, e suscitará reações não diferentes daquelas que 
experimentaríamos se tivéssemos presenciado o ocorrido.

Ou esses não são exemplos daquelas visões:

"Os olhos da coitada se regelam, sua roca se solta e suas lãs arrumadas no colo prestes caem"

"Com a ferida aberta em branco peito"

Aquele cavalo no funeral de Palante "despojado de insígnias"?

33. O quê? Não terá, do mesmo modo, o poeta capturado perfeitamente a imagem do momento derradeiro quando disse: "E se lembra, ao morrer, de Argos, a boa"? ${ }^{23}$ (Inst. or. VI, 2, 31-33)

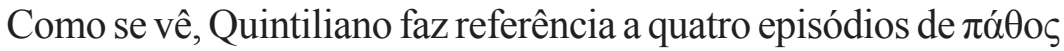
ascendente na trama da segunda metade da Eneida, respectivamente: o momento em que a mãe de Euríalo fica sabendo da morte de seu único filho (IX, 476); a morte e funeral de Palante (XI, 40; XI, 89) e, finalmente, o último suspiro de Ântor, o Argivo (X, 782). Convém sublinhar que Ântor, Palante e a mãe de Euríalo (a quem Virgílio não nomeia) são todos personagens menores - poderíamos incluir aí até Andrômaca, Polixena e a Sibila -, não obstante, Quintiliano os elege para demonstrar suas proposições.

O caso da mãe de Euríalo é representativo. Ela é a única mulher que continuou a viagem após o fatídico episódio na Sicília, em que, enganadas por Íris (que havia tomado a forma de Béroe), as mulheres

${ }^{23}$ XXXI. [Ad] Hominem occisum queror: non omnia quae in re praesenti accidisse credibile est in oculis habebo? non percussor ille subitus erumpet? non expauescet circumuentus, exclamabit uel rogabit uel fugiet? non ferientem, non concidenten uidebo? non animo sanguis et pallor et gemitus, extremus denique exspirantis hiatus insident? XXXII. Insequentur enargeia, quae a Cicerone inlustratio et euidentia nominatur, quae non tam dicere videtur quam ostendere, et adfectus non aliter quam si rebus ipsis intersimus sequentur. An non ex his uisionibus illa sunt:

excussi manibus radii reuolutaque pensa,

leuique patens in pectore uulnus,

equus ille in funere Pallantis positis insignibus?

XXXIII. Quid? non idem poeta penitus ultimi fati cepit imaginem, ut diceret: "Et dulcis moriens reminiscitur Argos"? 
troianas queimam as naus de Eneias (no livro V). A presença dela não é significativa até o livro IX, quando ela personifica, em última instância, os valores da misericordia, da pietas e do próprio $\pi$ ó $\theta$ os. Estamos de acordo com David Ross (2007, p. 42) quando ele afirma que "[Lauso] é o filho de um pai e, da mesma forma que a mãe de Euríalo parece estar ali porque é necessária para perfazer a imagem de seu filho, também Lauso parece ser essencial para a conversão de Mezêncio, uma outra variação do tema da pietas". A mãe de Euríalo chora, deseja a morte e faz um discurso lúgubre que espalha ainda mais agonia entre os troianos. Antes de causar maior estrago, ela é recolhida e silenciada por Áctor e Ideu.

A esse respeito, no De Inuentione, Cícero estabelece uma oportuna definição de conquestio:

(o lamento) é uma passagem que busca despertar a piedade do auditório. Nisto, a primeira necessidade é fazer com que o espírito do ouvinte esteja gentil e misericordioso, a fim de que ele possa ser mais facilmente comovido pela conquestio. Isto precisa ser feito através do uso de "lugares comuns" que demonstram o poder da fortuna sobre todos os homens e a vulnerabilidade da raça humana. Quando tal passagem é pronunciada com altivez e severidade, o espírito de um homem notavelmente se curva e se prepara para a piedade, já que ao vislumbrar a desgraça de outrem, ele contemplará sua própria fraqueza. ${ }^{24}(D e$ inu. I, 106)

Entre as categorias de conquestio que Cícero enumera, estão o lamento pela morte de uma criança amada, o elogio às crianças diante dos juízes e a tristeza pela separação de pais e filhos. Matthew Leigh (2004, p. 135-6) nos lembra de que a Retórica a Herênio (II, 50) oferece uma lista similar de abordagens para a evocação da misericórdia em uma peroração, e ali também são proeminentes tanto a preocupação com as crianças quanto os lamentos pelos reveses da Fortuna.

\footnotetext{
${ }^{24}$ Trad. nossa: Conquestio est oratio auditorum misericordiam captans. In hac primum animum auditoris mitem et misericordem conficere oportet, quo facilius conquestione commoueri possit. Id locis communibus efficere oportebit, per quos fortunae uis in omnes et hominum infirmitas ostenditur; qua oratione habita grauiter et sententiose maxime demittitur animus hominum et ad misericordiam comparatur, cum in alieno malo suam infirmitatem considerabit.
} 
Então, qual referência na época de Quintiliano poderia ter sido mais convencional e familiar do que a própria Eneida? Tendo sido mortos tragicamente Niso e Euríalo, a mãe deste último representa o clímax patético no livro IX, cuja temática versa, de modo geral, sobre a "falência da juventude", ou mais, a falência da inocência e da ação impulsiva. Uma conquestio como esta deve ter sido capaz de gerar piedade no próprio Turno.

Um exemplo de conquestio, nos moldes propostos por Cícero, pode ser encontrado no voto do ministro Marco Aurélio Mello, no âmbito da decisão sobre a descriminalização do aborto de feto anencefálico (ADPF 54). Em defesa da descriminalização, o principal elemento na estrutura argumentativa do ministro é recorrer à comoção de seus interlocutores. Para tanto, há a mobilização de argumentos que buscam despertar a compaixão.

Marco Aurélio faz uma oposição entre a gravidez normal e a gravidez anencéfala, apontando os inúmeros problemas, principalmente os psíquicos, pelos quais a mãe passa, ressaltando seu desespero e sofrimento. Depois de relatar um conjunto de diagnósticos psiquiátricos relacionados à temática, o ministro relata o sofrimento de uma mãe (o caso de Gabriela Oliveira Cordeiro), figura representativa para o caso que quer descrever, tal qual o exemplo da mãe de Euríalo. Com isso, seu objetivo é humanizar a figura da mulher, da mãe, descartando qualquer interpretação possível de que se trata de uma criminosa que cometeu aborto. Nitidamente, o foco é despertar ou aumentar a piedade do auditório:

(...) Um dia eu não aguentei. Eu chorava muito, não conseguia parar de chorar. O meu marido me pedia para parar, mas eu não conseguia. Eu saí na rua correndo, chorando, e ele atrás de mim. Estava chovendo, era meianoite. Eu estava pensando no bebê. Foi na semana anterior ao parto. Eu comecei a sonhar. O meu marido também. Eu sonhava com ela (referindo-se à filha que gerava) no caixão. Eu acordava gritando, soluçando. O meu marido tinha outro sonho. Ele sonhava que o bebê ia nascer com cabeça de monstro. Ele havia lido sobre anencefalia na internet. Se você vai buscar informações é aterrorizante. Ele sonhava que ela (novamente, referindo-se à filha) tinha cabeça de dinossauro. Quando chegou perto do nascimento, os sonhos pioraram. Eu queria ter tirado uma foto dela (da filha) ao nascer, mas os médicos não 
deixaram. Eu não quis velório. Deixei o bebê na funerária a noite inteira e no outro dia enterramos. Como não fizeram o teste do pezinho na maternidade, foi difícil conseguir o atestado de óbito para enterrar. (p. 40-41 do voto)

Outro exemplo de conquestio pode ser encontrado no voto do ministro Carlos Ayres Britto na ADI 3510, sobre a pesquisa com célulastronco. Em defesa da constitucionalidade das pesquisas, Ayres Britto recorre, em larga medida, ao despertar da piedade e da compaixão, usando exemplos de sofrimento de pais de filhos portadores de doenças degenerativas. As pesquisas com células-tronco têm - principal argumento de seus defensores - como um de seus focos a contribuição para o enfrentamento de doenças degenerativas. Para estes pais, os resultados das pesquisas acalentam a esperança de cura para seus filhos e para seu sofrimento. $\mathrm{O}$ ministro então assevera:

Como o juiz não deve se resignar em ser uma traça ou ácaro de processo, mas um ser do mundo, abro as minhas vistas para o cotidiano existencial do País e o que se me depara? Pessoas como Isabel Fillardis, fundadora de duas ONGs e conhecida atriz da Rede Globo de Televisão, a falar assim da síndrome neurológica de que padece o seu filhinho Jamal, de quatro anos de idade: "O Jamal tem West, uma síndrome neurológica degenerativa, que provoca crises compulsivas capazes de destruir áreas do cérebro. Quando você se depara com uma questão como essa, a primeira preocupação vai além do diagnóstico: o pai quer saber se o filho vai morrer ou será dado como louco. Ele chegou a ter 15 crises num dia. Comecei uma corrida contra o tempo, até achar a medicação própria para interromper as crises. Esse é um tempo de incerteza, que no nosso caso perdurou pelos dois primeiros anos de vida". (p. 64 do voto)

Todo o trecho é um convite ao interlocutor para que se coloque no lugar da mãe. Esse colocar-se no lugar (do outro) é exatamente o efeito produzido pela compaixão. Perceber que o sofrimento do outro poderia ser também o seu. O orador habilidoso, conforme descrição de Cícero, é capaz de fazer com que, através do argumento, o sofrimento seja, efetivamente, sentido pelo interlocutor. Ayres Britto, ao dar o exemplo da mãe que padece com a doença do filho, coloca em cena justamente a imagem do sofrimento. Seu argumento, a favor das pesquisas com células-tronco, 
firmará suas bases nessa imagem. O sofrimento de pais mostra o quão importante a pesquisa com células-tronco pode ser. Logo, não há motivos para vetar seu uso, devendo a lei de Biossegurança ser declarada como constitucional, permitindo o exercício de tais pesquisas. Seu argumento é pragmático, fazendo com que as causas recebam o mesmo valor que as consequências. Seu voto é estruturado em torno de uma conquestio.

\section{Conclusão}

É amplamente conhecido (e enfatizado pelo testemunho do próprio Quintiliano, Inst. or. X, 1, 27) o fato de que, entre outros propósitos, a lectio poetarum também tinha o papel de restaurar o espírito fatigado pela atividade forense. Ler os poetas, portanto, faz parte do ofício do orador e parece-nos razoável pensar que essa seja uma via de mão dupla. Se retórica e poesia diferem, em princípio, quanto aos objetivos (é comum designar aos poetas a função primordial de agradar, delectare, enquanto os oradores devem persuadir, persuadere), pode-se concluir, entretanto, que retórica e poesia também compartilham, em alguma medida e em meio a mútuos estímulos, estratégias para cativar a atenção dos ouvintes e relativizar uma contemplação direta dos fatos. $\mathrm{O}$ convite ao agrado exige, ele mesmo, a persuasão. Acreditamos que o tratado de Quintiliano sobre os afetos demonstra, essencialmente, que o discurso oratório, quando agrada aos olhos e aos ouvidos, alcançaria seu intento mais rápido e melhor, tornando-se muito mais persuasivo.

A análise conjugada do uso dos afetos e da poesia como estratégias retóricas em Quintiliano e, ampliando o foco na poesia para a literatura em geral, no STF brasileiro, aponta para a atualidade e importância do tema. Extrapolando os limites da teoria literária e da filosofia, as relações entre retórica e literatura (incluindo a poesia) mostram-se frutíferas para a compreensão da prática argumentativa em outras searas, no caso aqui analisado, o Direito.

O que vemos é que o recurso a argumentos oriundos de âmbitos exógenos ao campo jurídico é uma prática decisória do principal órgão do judiciário no Brasil, abrindo caminho para que argumentos extraídos da literatura (e de outras fontes), em prosa e poesia, integrem, reforcem e estruturem decisões. Tomando a fluidez argumentativa que caracteriza os diferentes gêneros de discurso, como já apontou Aristóteles, não há de se 
estranhar que essa seja uma prática não somente do judiciário nacional, mas, antes, de qualquer contexto do qual a retórica faça parte.

Assim, as relações entre poética e retórica, incluindo a incidência dos afetos, apontadas por Quintiliano na Roma imperial, ainda encontram paralelo em votos dos ministros do STF brasileiro, com uma ressalva: se Quintiliano defende a manipulação cuidadosa e moderada das emoções no discurso de seu orador ideal, situando a argumentação racional em primeiro plano, o que constatamos a partir da análise dos pareceres individuais nos hard cases apresentados é indefinição e imprevisibilidade sobre o tipo de argumento que deve vir em primeiro plano. Os recursos aos afetos e ao uso de argumentos literários, por exemplo, não se concentram particularmente na peroração, quando todos os recursos da lógica e da razão já foram esgotados. Mesmo na presença de argumentos pautados pela lógica, a mobilização do páthos e argumentos de naturezas distintas podem ser a opção do orador, tendo em vista seus interlocutores e os efeitos que deseja produzir. Aspectos circunstanciais influenciarão a decisão do orador em relação aos argumentos dos quais se valerá. Diante disso, afetos e literatura não são estratégias retóricas necessariamente secundárias, mas dependem da construção argumentativa do orador. Seguindo a proposta de Meyer (2007), essa é a característica da retórica contemporânea.

\section{Referências}

ARISTÓTELES. Poética. Trad. Ana Maria Valente. 3a ed. Lisboa: Calouste Gulbenkian, 2008.

ARISTÓTELES. Retórica. Trad. Manuel Alexandre Júnior, Paulo Farmhouse Alberto e Abel do Nascimento Pena. Lisboa: Imprensa Nacional, 1998.

BARTHES, R. L'ancienne rhétorique [Aide-mémoire]. In: BARTHES, R. (org.). Communications, 16 (Recherches rhétoriques). Paris: Seuil, 1970, p. 172-223.

BOURDIEU, P. O poder simbólico. $16^{\text {a }}$ edição. Rio de Janeiro: Bertrand Brasil, 2012.

CICERO. De inuentione; De optimo genere oratorum; Topica. With an English translation by H. M. Hubbell. Cambridge: Harvard University Press, 1949. 
DODDS, E. R. Os gregos e o irracional. Trad. Paulo Domenech Oneto. São Paulo: Escuta, 2002.

DUBOIS, J. et. alii (grupo $\mu$ ). Retórica da poesia: leitura linear, leitura tabular. Trad. Carlos Felipe Moisés. São Paulo: Cultrix, Editora da Universidade de São Paulo, 1980.

DWORKIN, R. Levando os direitos a sério. São Paulo: Martins Fontes, 2002.

HALL, J. Cicero and Quintilian on the oratorical use of hand gestures. Classical Quarterly, Cambridge, vol. 54 n. 1, 2004, p. 143-160.

LEIGH, M. Quintilian on the Emotions (Institutio Oratoria 6 Preface and 1-2). The Journal of Roman Studies, Cambridge, vol. 94, 2004, p. 122-140.

MAGALHÃES, R. F. Racionalidade e retórica: teoria discursiva da ação coletiva. Juiz de Fora: Clio Edições Eletrônicas, 2003.

MEDINA, P. R. de G. Direito processual constitucional. Rio de Janeiro: Editora Forense, 2005.

MEYER, M. A retórica. São Paulo: Ática, 2007.

PERELMAN, C. Retóricas. São Paulo: Martins Fontes, 2004.

PERELMAN, C.; OLBRECHTS-TYTECA, L. Tratado da argumentação: a nova retórica. São Paulo: Martins Fontes, 2005.

QUINTILIANO. Istituzione oratoria. Ed. Simone Beta \& Elena D'Incerti Amadio. Milão: Mondadori, 1997.

REZENDE, A. M. de. Rompendo o silêncio: a construção do discurso oratório em Quintiliano. Belo Horizonte: Crisálida, 2010a.

REZENDE, W. S. A retórica e o Supremo Tribunal Federal: o papel da argumentação na corte brasileira. 2010b. 196 f. Dissertação de mestrado. Programa de Pós-Graduação em Ciências Sociais da Universidade Federal de Juiz de Fora, 2010b.

REZENDE, W. S. As relações entre direito, política e sociedade: retórica e teoria da ação na análise da argumentação em casos difíceis no Supremo Tribunal Federal brasileiro. 2014. 523 f. Tese de doutorado. Programa de Pós-Graduação em Ciências Sociais da Universidade Federal de Juiz de Fora, 2014. 